\title{
"GIVING A VOICE TO 'UNFAMILIAR' OBJECTS" CHRISTIAAN JÖRG ON HIS PASSION FOR ASIAN ART
}

For thirteen years Christiaan Jörg held the chair of extraordinary professor in Material History of the Cultural Interactions between Asia and Europe. Jörg retired recently and a successor is being sought for the chair, which is financed by the Society of Friends of Asian Art. My conversation with this porcelain connoisseur took place in his house in Haren, where he lives with his wife and his personal collection of art works from Oceania.

There was not much art in his parent's house, says Christiaan Jörg (1944), "My father was a minister, and Protestants are not that involved with visual art. But I had a faded reproduction of a Japanese woodblock print by Utamaro in my bedroom that made a great impression on me, being representative of another world." He first saw ethnographic objects at the house of his parents' friends, including a collection of exotic musical instruments. He bought his first object - an Australian aboriginal shield - at a shop on the Denneweg in The Hague when he was 14 years old. Jörg initially started studying law in Leiden, but switched to art history. As one of his subsidiary subjects he chose Chinese art history, taught by the well-known Professor Zürcher. Asian art cast a spell over him and after graduating in decorative art he started focusing on the Orient. When asked for the reasons why all things Asian appeal to him, he pauses for a moment and responds with a very brief reply, "Emotion... a fascination with the 'other', with the exotic."

The university provided him with the opportunity to obtain his doctorate under the supervision of Professor Th.H. Lunsingh Scheurleer, the recognised expert in the field of Dutch interiors and a great advocate of studying original source materials. Jörg discovered a treasure trove of material in the National Archive, which houses the Dutch East India Company (VOC) archives. He immersed himself in the study of a still under-researched period in VOC history: the China trade during the 18th century. In 1978 he obtained his doctorate with his dissertation titled Porselein als handelswaar (Porcelain as a Trade Item), that was published in 1982 in a revised edition titled Porcelain and the Dutch China Trade. "It's nicknamed 'Jörg's telephone directory' because of the endless lists of all the types of objects that were shipped by the VOC," he remarks with a chuckle.

Shortly before his graduation Jörg was appointed curator of decorative arts at the Groninger Museum, which has a significant collection of Chinese and Japanese ceramics and porcelain, a position that encompassed the decorative arts of both the East and the West. He started by creating an inventory of the collection, which sharpened his interest in the interactions between Asia and Europe, and which has been his speciality ever since. The 1983 exhibition and publication in the Groninger Museum titled Oosters Porselein Pdelfts $_{11: 00: 44 \mathrm{Am}}$ Aardewerk. Wisselwerkingen (Interaction in Ceramics - Oriental Porcelain randccess 


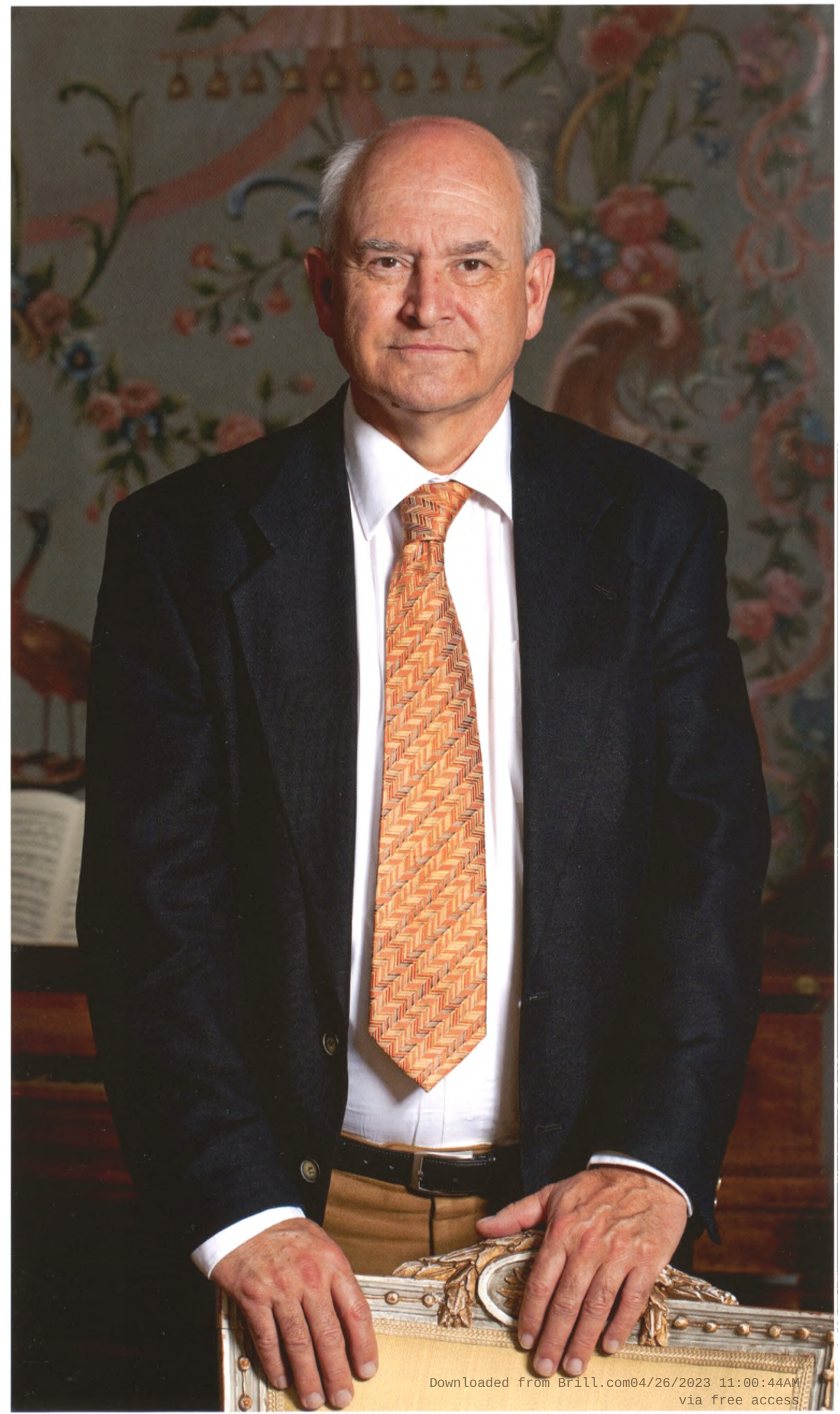


Delftware; English edition published in 1984) is an early manifestation of this interest.

Cultural interactions have always been Jörg's main focus, for instance, the comparison between the use of ceramics in the Japanese tea ceremony and the way that the Dutch drank their tea, and stored porcelain in cabinets and not in boxes. Export art became his main focus, especially the export porcelain that was made to order in China and Japan for Dutch customers. The latter subject received an enormous boost when the wreck of the Geldermalsen was discovered in 1985 . It sank in 1752 and remained undisturbed on the seabed in the Sunda Strait between the Indonesian islands of Java and Sumatra. It transpired that the hold of the ship contained a huge quantity of Chinese export porcelain, amounting to no less than 220.000 objects. The rows and rows of cups and saucers, bowls and plates confirmed that the scope of the porcelain trade conducted by the VOC was indeed as extensive as the archives suggested. In return for publishing his research into this porcelain just before the auction started at Christie's Amsterdam, he received one example of each type and variant from the ship for the Museum. This was the first time that such a comprehensive overview of a VOC shipment was acquired for research.

He was appointed deputy-director of the Groninger Museum in 1988, alongside the high-profile director Frans Haks, with whom Jörg did not always see eye-to-eye. "We already argued in the first week, but tried to work as a team and overall we succeeded rather well." He was later appointed Head of Collections and Head of Research in Groningen.

Christiaan Jörg also turned his sights on Japanese porcelain, and he held a visiting lectureship at Kansai University in Osaka in 1984 where he conducted research. His standard work on Japanese export porcelain in public and private collections in the Netherlands was published in 2003. And, of course, in true Jörg style he applied the results of his investigations to Dutch copies of Japanese porcelain.

Among other subjects, he also focused on Chinese ivory and Western chinoiserie, and a little later became deeply involved in the study of Japanese lacquerware, resulting in him co-authoring what is considered the standard work on this subject with his British colleague Oliver Impey (1936-2005) of the Ashmolean Museum, Japanese Export Lacquer 1580-1850. This book is the result of 15 years of research and it covers all the various types and styles of lacquerware. A striking conclusion is that the overall quality of Japanese lacquerware improved because of the pieces commissioned by the Dutch: "The best lacquered objects were made during the most intensive stages of the cultural interaction in the second quarter of the 17th century." The enormous diversity of lacquered objects was another surprise, ranging as it did from cabinets and jewellery boxes to tea tables. All these items were shipped to Amsterdam, at the time the European centre for exotica, where chintz and elephant ivory were also sold at the VOC auctions. "Sadly, very few of all those beautiful objects remained in the Netherlands," says Jörg, "The suggestion that lacquer cabinets were made solely to order for Dutch regents appears to be untenable. Most of it was sold immediately to foreign clients who took the objects out of the country." 
'Wisselwerkingen' ('Interactions'). In his lecture the recently appointed professor stated that his academic responsibilities included trying to create better insights into the holdings of museums in the Netherlands in the area of East-West interactions.

Besides students from the department of decorative art, some also came from courses such as Sinology and Japanology, two areas that in recent decades have attracted increasing numbers of students, reflecting the rapid growth of especially the Chinese economy. Students in colonial history and new courses such as Dutch Studies were also interested in Jörg's lectures and practical approaches. "The problem is that usually only one semester is allocated to this subsidiary subject, which means there isn't much time to truly accumulate knowledge. I could only convey the essence of the feeling of the objects, and this is why I was so keen on taking the students to museum storages where they could actually handle the objects and describe them firsthand." He also asked students to bring Oriental objects from their own or from their family homes to his lectures. "This was frequently a very successful exercise, sometimes they brought some very interesting pieces. I would also discuss their monetary value, much like the BBC's Antiques Roadshow television programme. This is also a way of sharing knowledge about art history, another way of opening students' eyes to other cultures." He occasionally had several genuinely interested students who conducted MA research under his guidance, while his Ph.D. students came not only from the Netherlands but also from England and Spain. Their dissertation subjects varied widely; from the reception of Chinese paintings in Europe in around 1900 to the Freemasonic networks in the Netherlands East Indies.

Christiaan Jörg has always championed collaborations between various museums in his area of specialisation. He celebrated his early retirement in 2003 with an exhibition in the Groninger Museum and an accompanying Dutch-English language catalogue titled Oriental Porcelain in the Netherlands. Four Museum Collections. The Amsterdam Rijksmuseum, the Gemeentemuseum The Hague, the Groninger Museum and the Princessehof in Leeuwarden have been collaborating since 2002, and have taken turns to present selections from their combined collections of Asian ceramics. Each museum maintains and is responsible for its own collection, and according to Jörg the collaboration works very well.

However, after his retirement in 2003 and because of the recent trend in the Netherlands whereby decorative arts are receiving less attention in art museums, no one was appointed to succeed him as curator of decorative art in Groningen. Of course, Jörg views this development with concern.

Christiaan Jörg's involvement with the Society started in the early 1980 s. He was chairman from 1996 to 2004, and served as interim-chairman from 2008 to 2010. He observed the profile of the members change between 1980 and 2000, "The collectors with extensive, typological or chronological collections have almost disappeared." The Van Diepen Collection, now preserved in the Fraeylemaborg in Slochteren is an example of this old type of collection, but fortunately it has been preserved in its entirety. "Van Diepen had a broad interest that spanned time and place when it came to collecting, but he also had his favourites, including Dutch Overdecorated Wares (Amsterdams Bont) which nobody else was particularly interested in at the time "om04/26/2023 11:00:44AM Partly as a result of this, the Society - and museums - receives considerablyaccess 
fewer gifts. Moreover, the rapidly rising prices at auctions over the last few decades also play a role and hamper connoisseurs with a small budget who still want to acquire truly worthwhile objects. "Knowledge about Asian art is on the decline. Acquiring knowledge is no longer the main goal; now it happens, for example, during holiday trips to Asian countries and because of the increasing interest in spirituality."

The recently retired extraordinary professor has also observed the changes underway at universities. "Students are less interested in gaining expertise. And they tend to avoid specialisations and select more 'global' subjects, to gain a broader overview of international cultures. They're also less concerned with theory, preferring more contact with the object instead."

During his various chairmanships he applied himself to developing new areas of collecting within the Society's collection that were not yet affected by the soaring prices, and to expanding the existing but under-represented subcollections. On the one hand this was a logical step to take because of the Society's limited financial resources, on the other, it was especially the intellectual and aesthetic pleasure of acquiring high-quality pieces from overlooked areas that appealed to him and the Board. Working closely with Menno Fitski, curator of East Asian Art at the Amsterdam Rijksmuseum, the Society concentrated on acquiring important Japanese paintings from the 19 th and 20th centuries.

He also initiated new policies which facilitated the long-term loan to other museums in the Netherlands of art works the Society received as bequests or gifts, but which do not fall within the redefined parameters of the Rijksmuseum with regard to the collection of Asian objects. As a result, lacquerware and ceramics from the Maartje Draak Bequest and porcelain from the Labroisse Gift now enrich the collections of Kasteel Heeswijk, the Groninger Museum and the Princessehof in Leeuwarden.

Jörg says that the relationship between the Society and the Rijksmuseum is "in excellent shape. Asian art has been fully integrated into the Rijksmuseum's overall collecting and acquisition policies. The pavilion that is now being constructed especially for the Asian department and which will also include the offices of four curators in this area are promising developments." His expectation is that the interest in Asian art will stimulate the bringing together in the near future of a comprehensive collection of Islamic art in the Netherlands. "This is really important because we trail behind other European countries in this field."

Museums have undergone significant changes in the last 20 years. Jörg: "Museums started concentrating on attracting as many visitors as possible. This is because they have to generate their own income to compensate for funding shortfalls. As a result, museums no longer prioritise those fields that only appeal to a limited specialised public, such as porcelain and decorative arts in general. And of course, this also means a concurrent reduction in the knowledge that will be gained by future generations."

He is not at all pessimistic about these developments, on the contrary. "Public interest in Asia and Asian cultures has increased substantially. As a consequence of the importance of Asian economies othe dailyngews/and 11:00:44AM political changes in Asia, this interest now also includes culture, but ${ }^{v}$ itais $^{\text {ree }}$ access 
more often motivated by empathy, and less by knowledge. Modern collections in this field often reflect the personalities of the collectors; they are a type of self portrait."

In addition, the new prosperity of a small group in Asian countries has resulted in Asian entrepreneurs starting to buy back their cultural heritage. This trend, which started in Japan in the 1970s, has taken hold in China and has consequently driven up the prices of Asian art considerably.

I asked him why he prefers to collect objects for his own collection from Oceania. "It is the blend of traditional craftsmanship, the often magical or ritual functions of the objects, and the completely different approach to design and the representation of perceived reality in this type of art that continues to interest me. The object is a unified concept, it is not made as an art object but is meant to imbue our existence with meaning." His wife Els Winkler, an artist herself, shares his thoughts about this, and their house testifies to their fascination.

Christiaan Jörg is still busy writing and publishing about his many interests. He recently wrote an essay about VOC imports of Chinese silks, a subject that has yet to be researched in depth. He found silk samples in the National Archive that reveal the demand and supply at the time. Among his many ongoing projects is an exhibition and catalogue about Chinese famille verte porcelain.

Towards the end of our conversation, I asked him again why Asia appeals to him so much, and this time he gave a more expansive - even poetic - answer, "To give a voice to an 'unfamiliar' object, using as much available information as possible. I am, in the end, a storyteller. That's probably because I'm the son of a minister, isn't it?" 